KHP Main \& Nose Wheel 개발을 위한 구조해석

김용환*, 이세욱*, 주영찬**, 지종호***, 조진수****

\title{
Structure Analysis of KHP Main \& Nose Wheel
}

Yong-Hwan Kim*, Sea-Wook Lee*, Young-Chan $\mathrm{Ju}^{* *}$, Chong-Ho Chi*** and Jin-Soo Cho****

\section{ABSTRACT}

This study performed the structure analysis for development and localization of main and nose wheel in Korean Helicopter Program(KHP). Structural stability of wheel is evaluated using ANSYS. Considering wheel and tire interface, Stress analysis was conducted by applying pneumatic of tire, static load, radial load and combined load on main and nose wheel. Considering yield strength at which plastic deformation occurs, simulation results suggest the method which increases structure stability after comparing maximum stress and yield strength.

$$
\text { 초 록 }
$$

본 연구는 $\mathrm{KHP}($ Korean Helicopter Program) main \& nose wheel 국산화 개발을 위한 구 조해석으로서 상용프로그램인 ANSYS를 사용하여 wheel의 구조적 안정성을 평가하였다. Wheel과 tire의 interface를 고려한 연구로서, Tire의 공기압과 정하중, 반경하중 그리고 복합 하중을 main \& nose wheel에 적용하여 응력해석을 수행하였다. 해석결과는 소성변형이 발 생하는 항복강도를 고려하여, maximum stress와 항복강도를 비교분석 후 구조적 안정성을 더 높일 수 있는 방안을 제시하였다.

Key Words : Korean Helicopter Program(KHP, 한국형 헬기 사업), Finite Element Method(유한요소법), Structure Analysis(구조해석), Wheel-Tire Interface(휠타이어 경계), Yield Strength(항복강도)

\section{I. 서 론}

한국형 헬리콥터 사업(KHP: Korean Helicopter Program)은 우리 군이 운용하고 있는 노후 된 기

\footnotetext{
† 2011년 11월 7일 접수 2012년 2월 17일 심사완료

* 정회원, 한양대학교 대학원 기계공학과

** 정회원, (주)다윈프릭션

*** 정회원, 국방기술품질원

**** 정회원, 한양대학교 기계공학부 교신저자, E-mail: jscho@hanyang.ac.kr 서울시 성동구 행당동 산 17
}

\begin{abstract}
동헬리콥터를 자체 개발한 기동헬리콥터로 대체 하는 사업이다[1]. 헬리콥터에 사용되는 휠은 고 정익에 비하여 더 많은 충격량을 고려하여 설계 하여야 하며, 현재 $\mathrm{KHP}$ 비행시제에는 개발 기간 및 비용에 대한 고려로 해외 업체에서 main wheel과 nose wheel을 단순 구매하여 사용하고 있다.

항공기는 착륙 시 발생하는 지상충격하중 및 동적거동이 설계에 적용되는 중요설계 변수이다 [2]. 다양한 하중 조건과 자세에서 착륙을 하기 때문에 응력 계산을 위하여 많은 경우를 고려해 야 하며, 그 중 특히 순간적인 충격 하중의 경우
\end{abstract}


를 가정하여 응력계산을 수행하여야 한다. 특히 헬리콥터의 main \& nose wheel은 착륙 및 제동 시 큰 하중을 받게 되며 이 하중을 견딜 수 있는 강도를 확보하기 위해서 설계 시 고려해야 한다.

휠에 관한 연구로서는 승용차용 알루미늄 휠 에 대한 충격시험방법인 ISO7141와[3], ISO충격 시험을 $\mathrm{CAE}$ (Computer Aided Engineering)를 활 용하여 수행한 구조해석[4][5], 휠과 tire의 interface에 관한 연구가 수행되었다[6]. 또한 충 격 완충장치가 적용된 소형항공기용 전방착륙장 치의 충격하중 해석에 관한 연구가 있다[7]. 공기 압을 포함한 tire의 응력해석에 관한 연구[8]와 $\mathrm{FEM}$ 을 이용한 자동차 tire의 simulation에 관한 연구가 수행되었다[9].

휠의 관한 연구가 매우 부족한 상황이며, 랜딩 기어와 같은 항공기 착륙장치에 관한 연구 및 자 동차용 휠의 충격시험을 바탕으로 한 연구가 선 행되었다. 휠과 tire에 interface에 관한 연구도 선행되었지만, 본 연구와 같이 휠과 tire의 interface를 고려하여, 정하중(static load), 반경하 중(radial load), 복합하중(combined load)과 같은 하중 조건을 적용한 구조해석 연구는 전무한 실 정이다.

본 연구에서는 wheel-tire interface[6], tire가 지면과 접촉하였을 시 공기압의 방향[9], 반경하 중이 가해졌을 시 tire의 변화, 공기압 tire에 가 로하중(side load) 적용 시 tire의 형태변형[8]을 고려하여 구조해석을 수행하였다. 충격 시 wheel 에 응력이 집중되는 부분과 변형이 일어나는 부 분을 파악함으로서 휠의 구조적인 내 충격성을 해석하였고, 항복강도와 국부응력이 발생하는 부 분을 비교하여 KHP main \& nose wheel의 구조 적 안정성을 평가하였다.

\section{II. 본 론}

\section{1 물성치 및 모델링}

본 연구에서 main \& nose wheel에 적용한 2014 Aluminum Alloy Die Forging의 물성치는 Table 1과 같다. Young's Modulus, Shear Modulus 및 Poisson's Ratio 등의 물성치를 적용 하였다[10].

Figure 1(a)와 (b)는 각각 main wheel과 nose wheel을 모델링 한 것으로서, Inboard와 outboard 를 표시하였다. Main \& nose wheel의 구조해석
에 사용될 유한요소는 Fig. 2에 나타낸 바와 같 이 3차원 10 노드 요소인 Tetrahedral Structural Solid 를 사용하였다[11]. Fig. 3(a)는 main wheel 의 유한요소모델로서, 약 120 만개의 절점과 약 70만개의 요소로 구성하였다. Fig. 3(b)는 nose wheel의 유한요소모델로서, 약 100 만개의 절점과 약 60 만개의 요소로 구성하였다.

Table 1. 2014 Aluminum Alloy Die Forging

\begin{tabular}{|l|r|}
\hline Young's Modulus & $72.4 \mathrm{GPa}$ \\
\hline Shear Modulus & $28.0 \mathrm{GPa}$ \\
\hline Tensile Yield Strength & $380 \mathrm{MPa}$ \\
\hline Compressive Strength & $470 \mathrm{MPa}$ \\
\hline Poisson's Ratio & 0.33 \\
\hline
\end{tabular}

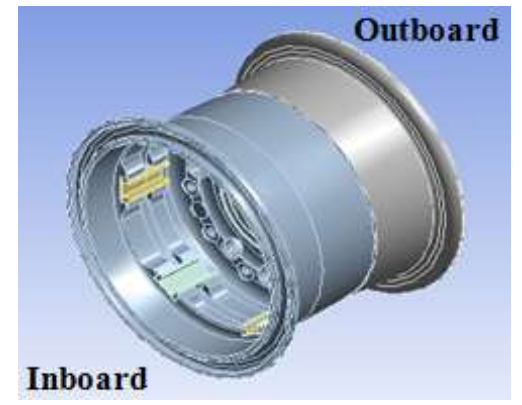

(a) Main Wheel

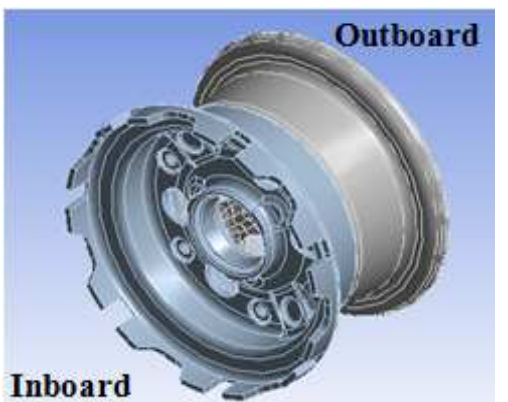

(b) Nose Wheel

Fig. 1. Modeling of Main \& Nose Wheel

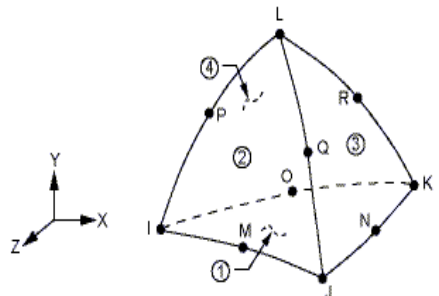

Fig. 2. 3-D 10-Node Tetrahedral Structural Solid 


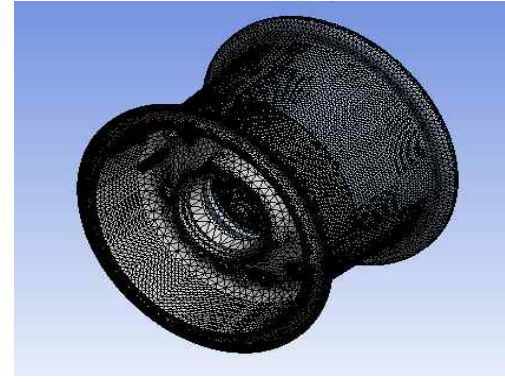

(a) Main Wheel

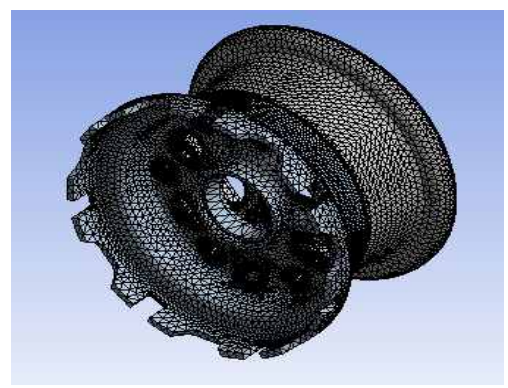

(b) Nose Wheel

Fig. 3. Finite element model of Main \& Nose Wheel

\section{2 하중조건 및 해석조건}

본 연구에서 main \& nose wheel의 하중조건 은 (주)한국항공우주산업에서 제시한 헬기용 하 중조건을 적용하였다. Main wheel의 하중조건은 정, 반경 그리고 복합하중을 적용하였다. 복합하 중은 반경하중과 가로하중을 동시에 적용하였으 며, 휠의 inboard, outboard의 방향으로 가로하 중을 적용하였다.

반경하중은 휠의 수직방향으로 설정하였고, 가로하중은 inboard, outboard의 수평방향으로 설정하였다. 휠과 지면의 접촉이 가까운 림(rim) 및 플랜지(flange)와 튜브웰(tubewell) 부분에 가 로하중을 적용하였다. 전체적으로 nose wheel보 다 main wheel에 가해지는 하중을 더 크게 적용 하였다.

본 연구는 tire를 고려하여 휠의 구조해석을 실행하였으므로, tire의 inflation pressure load 및 tire-wheel interface를 고려하였다[6]. Main \& nose wheel의 shaft 부분을 구속조건으로 fixed 하고, 정, 반경, 복합하중을 휠에 적용하였다. 정, 반경하중은 수직하중이 작용하는 형태로 적용하 였으며, 복합하중은 수직하중 뿐만 아니라 가로 하중을 적용하였으며, tire의 변형을 고려하여 적 용하였다[7]. 휠의 튜브웰 부분은 tire에 의한 공 기압하중을 적용하였다[6][8].

\section{III. 결과 및 검토}

\subsection{Main Wheel의 해 석결과}

본 연구에서는 main wheel의 구조적 안정성 평가를 위해 Von-Mises 항복조건을 적용하여 구 조해석을 수행하였다. Fig. 4(a)는 main wheel의 복합하중(ultimate) inboard의 해석결과로서, 정, 반경하중의 해석결과 또한 (a)와 유사한 응력분 포를 보인다. 하지만 복합하중의 경우에서는 정, 반경하중과 다르게 가로하중의 방향에 따라 립 및 플랜지에 분포되는 응력이 비교적 크게 나타 났다.

Figure 4(b), (c)에서는 국부응력이 발생하는 부분을 나타내었다. main wheel의 inboard와 outboard가 맞닿는 부분과, 볼트가 체결되는 부위

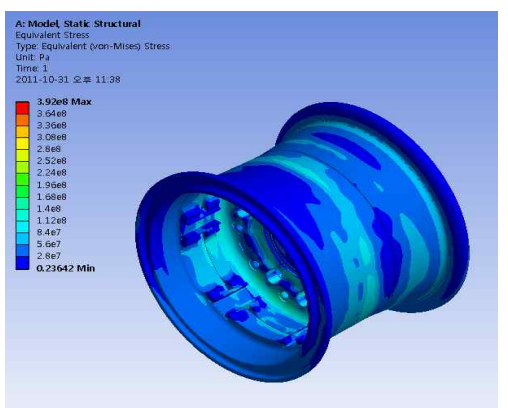

(a) Equivalent Stress of Main Wheel

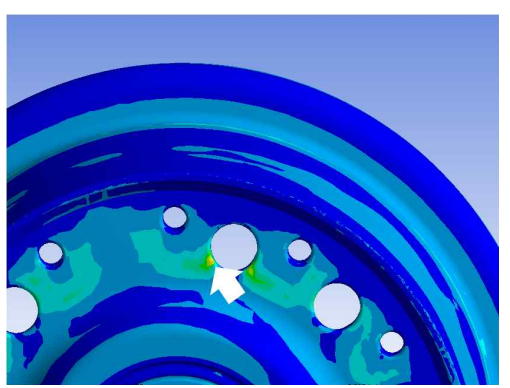

(b) Maximum Stress of Main Wheel

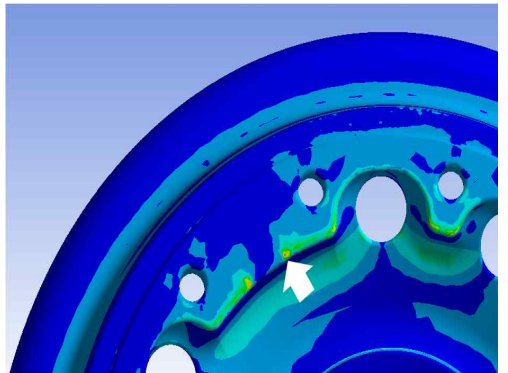

(c) Maximum Stress of Main Wheel

Fig. 4. Analysis Result of Main Wheel 


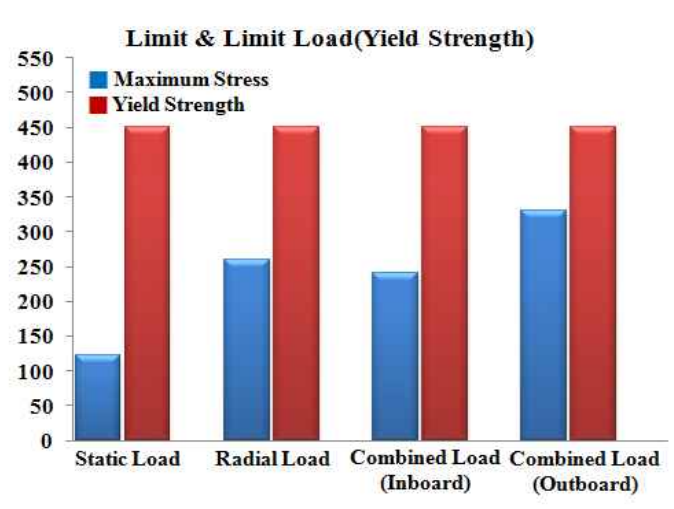

(a) Comparison of Limit Load Results ( $\mathrm{MPa}$ )

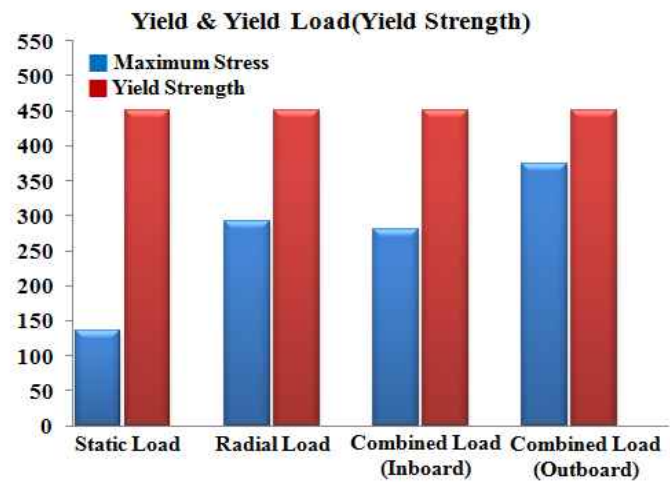

(b) Comparison of Yield Load Results (MPa)

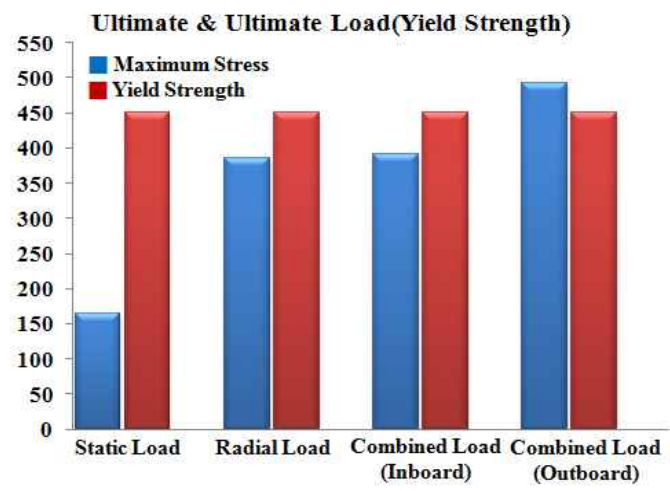

(c) Comparison of Ultimate Load Results (MPa)

Fig. 5. Comparison of the Main Wheel Results

에서 국부응력이 발생하였다. 국부응력이 발생하 는 부분과 림 및 플랜지, 스포크(spoke)부분에서 비교적 응력분포가 크게 형성되었다.

Figure 5(a), (b), (c)에서는 limit, yield, ultimate load 에서 각각 정, 반경, 복합하중에 발생하는 maximum stress와 항복강도를 비교하 였다. 항복강도는 인장항복강도(tensile yield streng고)인 $450 \mathrm{MPa}$ 로 설정하였다. (a)와 (b)는
국부응력이 항복강도를 초과하지 않음을 볼 수 있다. 그러나 (c)는 복합하중(outboard)에서 약 $40 \mathrm{MPa}$ 정도의 차이로 국부응력이 항복강도 보 다 크게 나타났으며, 복합하중에서는 inboard보 다 outboard에서 국부응력과 항복강도의 차이가 더 크게 나타났다.

\subsection{Nose Wheel의 해석결과}

Nose wheel의 복합하중(ultimate) inboard 해 석결과는 전체적으로 Fig. 6(a)와 같은 응력분포 를 보인다. Nose wheel의 경우도 main wheel과 마찬가지로, 가로하중의 방향에 따라 림 및 플랜 지 그리고 스포크에 분포되는 응력이 비교적 크 게 나타났다. Main wheel에 비해 응력분포가 크 게 나타났다.

Figure 6(b)에서는 국부응력이 발생하는 부분 을 나타내었다. 국부응력은 nose wheel의 inboard 림 부분으로서, 반경하중이 작용하는 부 분의 림에 발생하였다.

Figure 7(a), (b), (c)에서는 limit, yield, ultimate load 에서 각각 정, 반경, 복합하중에 발생하는 maximum stress와 항복강도를 비교하 였다. 전체적으로 국부응력이 항복강도를 초과하 지 않음을 볼 수 있다.

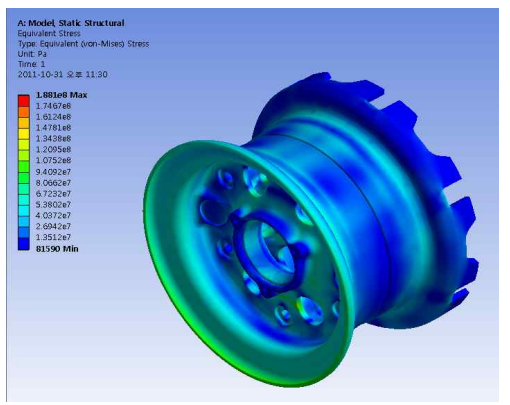

(a) Equivalent Stress of Nose Wheel

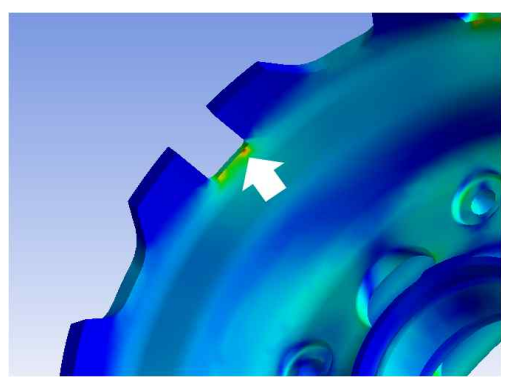

(b) Maximum Stress of Main Wheel

Fig. 6. Analysis Result of Nose Wheel 


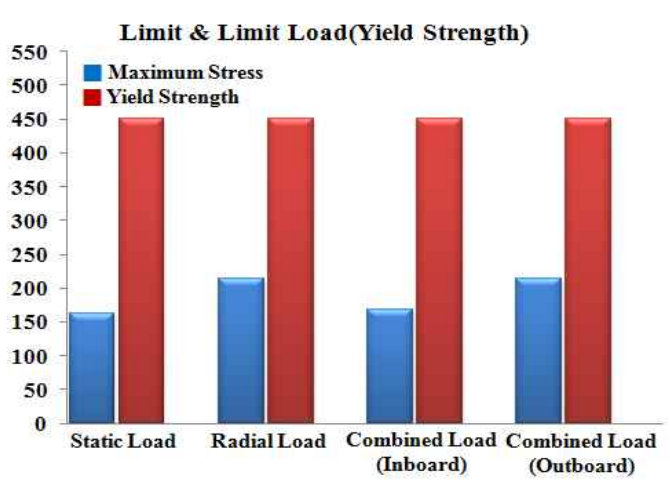

(a) Comparison of Limit Load Results ( $\mathrm{MPa}$ )

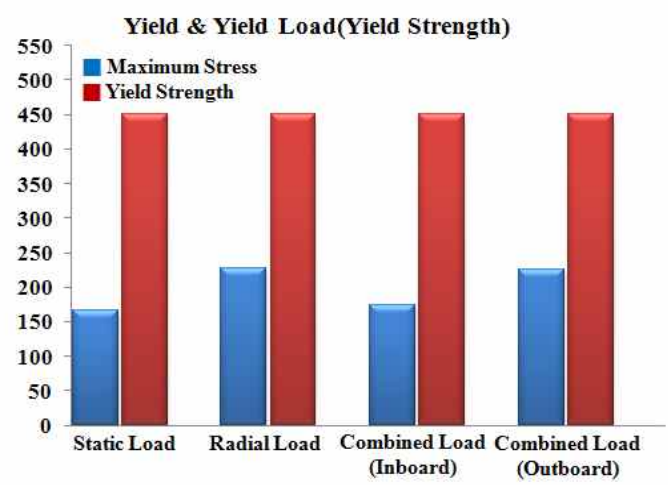

(b) Comparison of Yield Load Results ( $\mathrm{MPa}$ )

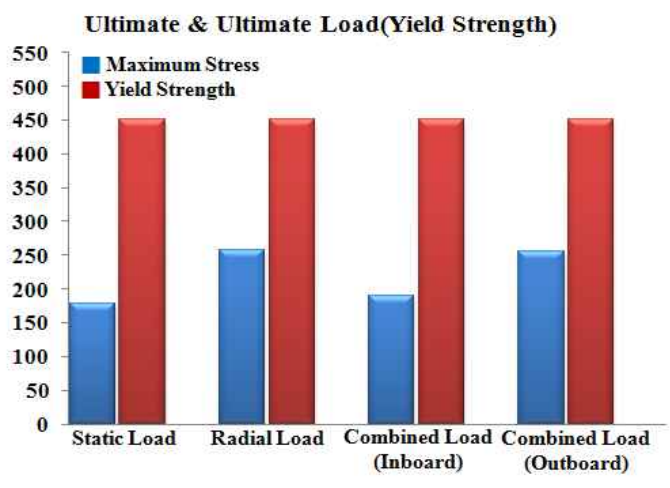

(c) Comparison of Ultimate Load Results ( $\mathrm{MPa}$ )

Fig. 7. Comparison of the Nose Wheel Results

\section{IV. 결 론}

본 연구에서는 KHP용으로 개발될 main \& nose wheel에 대해 (주)한국항공우주산업에서 제 시한 헬리콥터용 하중조건을 적용하여 구조해석 을 실행하였다.

해석결과 휠의 스포크 부분과 wheel-tire 접지
부분인 림과 플랜지 부분에 응력이 크게 작용함 을 볼 수 있다. 또 inboard와 outboard가 맞닿는 부분, 볼트가 체결되는 부위에서 응력이 크게 작 용하며, main wheel에서는 국부응력이 발생하였 다. Nose wheel은 형상적인 부분에 의하여 림의 tip부분에서 국부응력이 발생하였다.

각각의 하중조건의 안전계수를 도출하면, Main wheel에서는 0.92 부터 3.6 의 값을 보인다. 복합하중(outboard)에서 항복강도가 요구강도보 다 높게 나왔으나, 복합하중(inboard)와 정, 반경 하중에서는 모두 1이 넘는 안전계수 값이 도출되 었다. Nose wheel에서의 안전계수는 1.75 부터 2.78 의 값이 도출되었으며, 모두 안전계수 1 이 넘 는 수치를 나타내었다. Main wheel 복합하중 (outboard)의 구조적 안정성을 보강한다면, 그 외 의 하중조건에서는 비교적 안정적이라 평가할 수 있다.

Main wheel과 같이 발생한 국부응력은 볼트 를 체결함으로서 inboard와 outboard의 구속을 강화하고, 볼트체결부위의 안정성을 높여 응력이 집중되는 현상을 완화할 수 있을 것으로 예상된 다. Nose wheel에서의 국부응력은 형상적인 문 제로서, 각(角)과 같이 edge한 부분에 응력이 집 중되는 원리로 예상된다. 이러한 국부응력은 라 운딩 또는 모따기와 같은 작업을 통해 국부응력 을 완화할 수 있다.

본 연구를 통하여 한국형 헬리콥터산업 및 항 공산업의 부품 개발 기술 국산화에 도움이 될 것 으로 예상된다.

\section{후 기}

본 연구는 중소기업기술개발 지원사업 위탁연 구개발 과제 수행중의 일부임.

\section{참고문헌}

1) 한국항공우주산업진흥협회, 방위사업청 $\mathrm{KHP}$ 사업단, "한국형 헬기사업 추진현황".

2) 이상일, 김영만, 심주영, "KT-1 계열 항공 기용 주륜착륙장치의 성능 해석", 한국항공우주 학회 춘계학술발표회 논문집 2006. 4, pp211-214.

3) ISO 7141, "Road vehicles-wheels-Impact test procedure"

4) Chang Chia-Lung, Yang Shao-Huei, "Simulation of wheel impact test using finite 
element method", ENGINEERING FAILURE ANALYSIS Volume 16, Issue 5, pp1711-1719.

5) WC Chang, "Modeling for Impact Test of Aluminum Wheels", 2008

6) J. A. Sherwood, J. M. Ayres, T. S. Gress and D. Watt, "AN INVESTIGATION OF TIRE-WHEEL INTERFACE LOADS USING ADINA" Computers \& Structures Volume 56, Issues 2-3, 17 July 1995, pp377-387

7) 박일경, 최선우, 장재원, "소형항공기 올레 오 타입 전방착륙장치 충격해석", 한국항공우주 연구원, 항공우주기술, 제 6권 제 1호, 2007. 7, pp19-28

8) 조재웅, 한문식, “노면에 접촉된 자동차 타이어의 응력 해석" 한국기계가공학회, 제8권2009. 6, pp40-45
9) Masaki Shiraishi, Hiroshi Yoshinaga, Naoaki Iwasaki, Kimihiro Hayashi "Making FEM Tire Model And Applying It For Durability Simulation" 6th International LS, 2000.

10) MIL-HDBK-5J, Metallic Materials and Elements for Aerospace Vehicle Structures, 31, JAN, 2003.

11) ANSYS, Release 11.0 Documentation for ANSYS.

12) 최창근, “유한요소법(Finite Element Method)", 대한토목학회, 대한토목학회지, 제36권 제3호, 1988. 6, pp39-44

13) 김낙수, 김형종, 소성가공과 해석, 도서출 판 문운당, 2002. 